\title{
ZIna, Qadzaf, dan Minuman Keras Dalam Perspektif Hukum Pidana Islam*
}

\author{
(ZINA, QADZAF, AND LIQUOR IN THE PERSPECTIVE \\ OF ISLAMIC CRIMINAL LAW)
}

\author{
Hamid Farihi \\ Fakultas Syariah dan Hukum UIN Jakarta \\ Jl. Ir. H. Juanda No. 95 Ciputat Tangsel \\ E-mail: hamid.farihi0@gmail.com
}

\begin{abstract}
The conception of Islam in particular concerning criminal law, can basically be taken into consideration as well as input for the development of national laws in the future. Therefore, it would need to be pursued in earnest to provide input to the relevant parties, both government and legislative branches to work together to realize the national criminal law in accordance with the aspirations and expectations of the people.
\end{abstract}

Keywords: Criminal, Islamic and Legal Development

\begin{abstract}
Abstrak: Konsepsi ajaran Islam khususnya yang menyangkut hukum pidana, pada dasarnya dapat dijadikan bahan pertimbangan serta masukan bagi pembinaan hukum nasional di masa yang akan datang. Oleh karena itu kiranya perlu diupayakan secara sungguh-sungguh untuk memberikan masukan kepada para pihak yang terkait, baik instansi pemerintah maupun lembaga perwakilan rakyat untuk bersama-sama mewujudkan hukum pidana nasional yang sesuai dengan aspirasi dan harapan umat.
\end{abstract}

Kata Kunci: Pidana, Keislaman, dan Pembinaan Hukum

* Diterima tanggal naskah diterima: 23 Maret 2014, direvisi: 18 April 2014, disetujui untuk terbit: 24 Mei 2014. 


\section{Pendahuluan}

Situasi krisis multidimensi yang berkepanjangan yang menimpa bangsa Indonesia dewasa ini, dalam pandangan agamawan, boleh jadi merupakan peringatan Tuhan agar bangsa ini sadar dan mau memperbaiki diri dengan kembali ke jalan yang benar dan diridhai Tuhan. Peringatan Tuhan semacam ini dalam sejarah umat manusia telah berulang kali terjadi dan menimpa mereka yang lupa diri, lupa mensyukuri nikmat serta karunia Ilahi. Mereka mengkufuri nikmat tersebut, bahkan menggantinya dengan berbagai macam maksiat dan kejahatan termasuk pelanggaran menyangkut nilai-nilai dan moralitas agama. Ketidakadilan, ketamakan, penyalahgunaan wewenang, korupsi, kolusi, nepotisme, pelanggaran HAM, pergaulan bebas, perselingkuhan, merupakan deretan panjang bentuk-bentuk kejahatan dan pelanggaran yang mencerminkan pelecehan terhadap wibawa hukum dan perundang-undangan, serta pengabaian terhadap moralitas keagamaan.

Hal ini dimungkinkan antara lain karena lemahnya perangkat hukum yang mengatur, mengendornya kontrol masyarakat, hilangnya wibawa aparat penegak hukum dan pemerintahan, dan yang lebih mendasar lagi adalah akibat lemahnya iman dan ketakwaan yang menjadi dasar bagi kesejahteraan lahir batin seperti yang dijanjikan Tuhan.

Untuk memperbaiki keadaan seperti ini, agar tidak semakin terperosok ke dalam kekacauan masyarakat (social disorder), maka agama menawarkan suatu terapi dan solusi yang tentunya dapat ditempuh bangsa ini yaitu dengan kembali kepada ajaran Ilahi, yaitu kembali kepada ajaran yang menghargai moral dan martabat kemanusiaan, yang mendambakan kesejahteraan masyarakat secara lahir maupun batin serta menjunjung tinggi supremasi hukum dan perundang-undangan yang sesuai dengan nilai-nilai keislaman. Dengan kata lain, bangsa ini mestilah dibawa kepada ajaran yang dapat memperkuat keimanan dan ketakwaan kepada Allah Swt.. Apabila ini dapat tercapai, maka sesuai dengan janji-Nya, Allah Swt. akan memberikan kemakmuran dan kesejahteraan dengan membuka segala keberkahan dari langit dan bumi seperti termaktub dalam firman-Nya, dalam surat al-A'raf: 96:

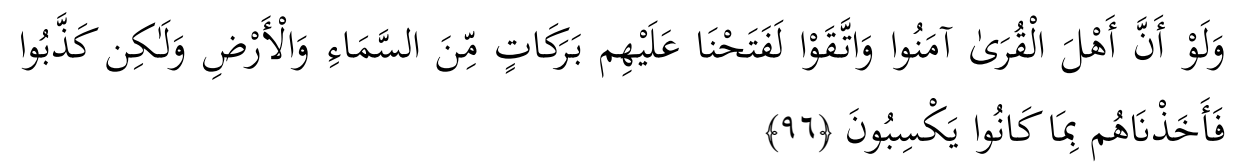


"Jikalau sekiranya penduduk negeri-negeri, beriman dan bertaqwa, pastilah Kami akan melimpahkan kepada mereka berkah dari langit dan bumi, tetapi mereka mendustakan (ayat-ayat Kami) itu, maka Kami siksa mereka disebabkan perbuatan mereka." (QS. Al-A'raf: 96).

Mantapnya keimanan dan ketakwaan, dalam pandangan agama dicerminkan dalam bentuk tingginya penghargaan dan pemeliharaan terhadap enam pilar syariat yang menjadi penopang kemaslahatan umat, yaitu pemeliharaan dan perlindungan terhadap agama, jiwa, harta, akal, nasab, dan kehormatan.

Sebagaimana diketahui, hukum pidana yang ada sekarang ini belumlah memadai bila dilihat dari perspektif keislaman. Hukum pidana yang menyangkut delik perzinahan umpamanya, masih menyisakan titik lemah yang harus diperbaiki. Delik ini hanya menjangkau mereka yang terikat dalam ikatan perkawinan. Itupun bila ada pengaduan dari pihak yang merasa dirugikan. Mereka yang masih lajang jika melakukan perzinahan secara suka rela, tidaklah terjangkau oleh hukum pidana ini. Padahal bila dilihat dari pandangan agama, pelanggaran seksual semacam ini merupakan larangan bagi setiap umat beragama dari agama apapun yang dipeluknya. Setiap agama, terutama agama samawi, melarang segala bentuk perzinahan, tidak terkecuali mereka yang berada di luar ikatan perkawinan.

Oleh karena itu kiranya perlu upaya yang sungguh-sungguh untuk memberikan masukan kepada para pihak yang terkait, baik instansi pemerintah maupun lembaga perwakilan rakyat untuk bersama-sama mewujudkan hukum pidana nasional yang sesuai dengan aspirasi dan harapan umat. Disamping itu perlu pula upaya untuk mengkomunikasikan hukum pidana Islam kepada masyarakat luas agar mereka tidak memperoleh gambaran yang keliru tentang hukum pidana Islam tersebut.

Dalam rangka mencari rumusan yang tepat sesuai dengan kepribadian serta nilai-nilai luhur bangsa ini, maka dirasa penting untuk mengedepankan topik bahasan seperti yang tercantum sebagai judul makalah ini. Dengan harapan tentunya, pada saatnya nanti konsepsi ajaran Islam khususnya yang menyangkut hukum pidana, kiranya dapat dijadikan bahan pertimbangan serta masukan bagi pembinaan hukum nasional di masa-masa mendatang, dalam rangka ikut menyambut terwujudnya masyarakat madani yang dicitacitakan, yang menjunjung tinggi supremasi hukum dan perundang-undangan serta menegakkan moralitas agama dan keadilan. 
Sebagaimana diketahui, dalam syariat Islam ada enam aspek yang menjadi pilar syariat yang harus dilindungi dan dipelihara sebagai penunjang kemaslahatan umat. Enam aspek tersebut ada1ah: agama, jiwa, akal, harta, nasab dan kehormatan. ${ }^{1}$ Untuk memelihara keenam aspek inilah syariat menetapkan berbagai sanksi pidana berupa: hudud, qishash dan ta'zir.

Untuk memelihara agama, agar orang tidak mudah keluar dari Islam (murtad) syariat menetapkan sanksi pidana (had) yang berat baginya. Untuk memelihara keselamatan jiwa, syariat menetapkan hukuman balas (qishash) bagi mereka yang membunuh orang lain tanpa hak. Hukuman dera yang diberikan atas orang yang berzina adalah untuk memelihara nasab (keturunan). Untuk memelihara harta, syariat Islam menetapkan hukuman potong tangan atas pelaku pencurian. Untuk memelihara kehormatan ('irdh) seseorang, Islam menetapkan hukuman qadzaf bagi mereka yang menuduh orang lain melakukan perzinahan. Hukuman dera atas orang yang mabuk diberikan untuk memelihara akal. Dasar pemikiran (logika) yang dipergunakan dalam hal ini adalah jika seseorang yang berniat mabukmabukan kemudian ia tahu jika mabuk akan didera, maka ia akan mengurungkan niatnya. Dengan demikian akan terpeliharalah akal sehatnya. Demikian pula hukuman balas (qishash) dimaksudkan agar orang yang bermaksud membunuh orang lain, ketika ia tahu akan dibalas dengan hukuman mati, tentu ia akan sadar dan mengurungkan niatnya. Dengan begitu terpeliharalah jiwa orang lain, demikianlah seterusnya logika pemberian hukuman pada tindak pidana lainnya. ${ }^{2}$

Jarimah hudud adalah tindak kejahatan yang membahayakan keamanan dan ketertiban masyarakat (hak Allah) yang diancam dengan hukuman had. Hukuman had adalah hukuman yang kadarnya telah ditetapkan syariat dalam Alquran atau Sunnah. Oleh karena hak Allah, jarimah had ini tidak bisa gugur walaupun ada pemberian maaf dari pihak yang dirugikan. Yang termasuk kategori jarimah hudud adalah: zina, qadzaf, mabuk miras, mencuri, hirabah (penyamunan), riddah (keluar dari Islam), dan gerakan makar (bughat).

Sedangkan jarimah qishah (balas) adalah tindak kejahatan yang merugikan perorangan (hak al-adami) yang diancam dengan hukuman balas (qishash). Oleh karena jarimah ini menyangkut perorangan (hak al-adami),

\footnotetext{
${ }^{1}$ Al-Sayyid al-Bakri, I'anah al-Thalibin, (Beirut: Dar al-Fikr, 1993), Jilid 4, hlm. 161.

${ }^{2}$ Al-Sayyid al-Bakri, I'anah al-Thalibin, hlm. 161.
} 
maka hukumannya dapat gugur atau berubah apabila ada pemberian maaf dari pihak yang dirugikan. Yang termasuk dalam jarimah ini adalah jarimah pembunuhan, dan penyerangan pihak lain.

Sedangkan jarimah $t a^{\prime} z i r$ adalah tindak pelanggaran yang menyangkut kepentingan umum dimana ketentuan hukumannya tidak ditentukan oleh syariat, tetapi diserahkan kepada kebijaksanaan Hakim. Hukuman ta'zir ini dimaksudkan untuk memberikan pelajaran ( $\left.t a^{\prime} d i b\right)$ kepada pelaku pelanggaran. Hukuman $t a^{\prime} z i r$ bisa berbentuk ucapan, seperti teguran atau nasehat, dan dapat berupa hukuman fisik seperti: penjara, pemukulan (cambuk), pengasingan (mutasi), pemecatan, pembebasan tugas, penggundulan rambut. ${ }^{3}$

\section{Tindak Pidana (Jarimah) Zina}

Jarimah zina dipandang sebagai tindak pidana berat yang menempati ranking kedua akbar al-kaba'ir setelah pembunuhan. Hal ini dipertegas dengan adanya larangan keras Allah Swt. dalam surat al-Isra' ayat 32:

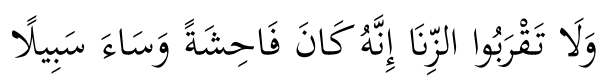

"Dan janganlah kamu mendekati zina; sesungguhnya zina itu adalah suatu perbuatan yang keji dan suatu jalan yang buruk." (QS. Al-Isra: 32).

Ulama Syafi'iyah mendefinisikan zina sebagai: “Memasukkan zakar ke dalam farji terlarang karena zatnya tanpa ada syubhat' dan disenangi menurut tabi'atnya."4

$$
\text { الزنا هو إيلاج الذكر بفرج محرم لعينه خال من الشبهة مشتهى طبعا }
$$

Dari klausul "'ke dalam farji" dalam definisi ini dipahami bahwa memasukkan zakar bukan ke dalam farji tidaklah dinamakan zina, tetapi dinamakan liwath (sodomi) jika memasukkannya ke dalam dubur (anal). Bukan pula zina, jika memasukkannya ke dalam mulut (oral sex). Sedangkan dari klausul "tanpa syubhat", dipahami bahwa jika ada syubhat maka tidak

${ }^{3}$ Al-Sayid Sabiq, Fiqh al-Sunnah, (Beirut: Dar al-Fikr, 1983) Cet. Ke-4, Jilid 2, hlm. 302 dan hlm. 497.

${ }^{4}$ Abdul Qadir 'Audah, al-Figh al-Jina'I al-Islami, (Beirut: Dar al-Fikr, 1968), Cet. Ke-5, Jilid 2, hlm. 349. 
pula termasuk zina seperti bila bersetubuh dengan wanita lain yang disangka isterinya sendiri: juga termasuk syubhat jika bersetubuh dengan wanita yang dikawini melalui nikah mut'ah atau pernikahan lain yang mengandung kesalahan prosedur, seperti nikah tanpa wali, atau nikah tanpa saksi. Terhadap kasus pelanggaran seperti ini tetap dikenakan ta'zir dan bukan had zina. Dari klausul "disenangi menurut tabi'atnya", dikecualikan bila menyetubuhi wanita yang sudah meninggal. ${ }^{5}$

Demikian pula tidak termasuk zina, jika menyetubuhi isteri yang dalam keadaan haid, nifas, sedang berpuasa, sedang haid, dalam masa li'an atau zhihar. Semua ini diharamkan walaupun tidak dianggap perzinahan. Termasuk dalam kategori ini pula jika memasukkan kelamin antara dua paha wanita lain (sihaq), atau dengan bersenang-senang di luar farji. Semua ini diharamkan, sama dengan diharamkannya mencium, merangkul, bercumbu dan tidur dalam satu selimut dengan wanita lain. ${ }^{6}$

Suatu hal yang dipermasalahkan adalah jika persetubuhan itu dilakukan dengan cara yang aman seperti dengan menggunakan kondom atau alat-alat kontrasepsi lain. Ini semua tetap diharamkan bila dilakukan terhadap wanita lain, termasuk hubungan bebas antar remaja. Walaupun illat hukum berupa tercampurnya nasab (ikhtilath al-nasab) dalam hal ini mungkin dapat dihindari, perbuatan tersebut tetap merupakan jarimah fakhisyah (pelanggaran seksual) yang diharamkan.

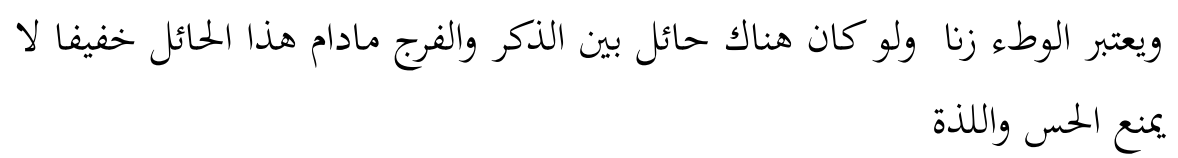

"Termasuk tindak perzinahan, walaupun dilakukan dengan memakai penghalang tipis (kondom)."

\section{Wathi' Dubur (Anal Sex)}

Mayoritas fuqaha, di antaranya Malik, al-Syafi'i, Ahmad,Syi'ah, dan Zaidiyah memandang bahwa wathi' dubur atau analsex itu hukumnya haram dan dengan demikian diancam hukuman had. Jika pelakunya muhshan dijatuhi hukuman rajam (bunuh), dan jika masih lajang dihukum cambuk dan

\footnotetext{
${ }^{5}$ Abdul Qadir 'Audah, al-Figh al-Jina'I al-Islami, hlm. 350.

${ }^{6}$ Abdul Qadir 'Audah, al-Fiqh al-Jina'I al-Islami, hlm. 351.
} 
dibuang selama setahun. Sedangkan Abu Hanifah memandang wathi' dubur itu bukan zina. Ia membedakan antara farji dengan wathi' dubur. Yang pertama disebut zina dan diancam dengan had. Sedangkan yang kedua disebut liwath, dan diancam dengan hukuman ta'zir, baik terhadap laki-laki maupun perempuan, keduanya diancam dengan hukuman $\mathrm{t} a^{\prime} z i{ }^{\prime} .^{7}$

Sedangkan orang yang melakukan liwath terhadap isterinya sendiri, maka mayoritas fuqaha memandangnya sebagai penyimpangan seks yang diharamkan dan dikenakan sanksi ta'zir. Hanya saja menurut al-Syafi'iyah, ta'zir tersebut diberikan setelah ada peringatan dari Hakim. Apabila diulangi setelah diperingati, maka barulah Hakim menjatuhkan sanksi $t a^{\prime} z i r .{ }^{8}$

\section{Syubhat dalam Hubungan Kelamin (Wathi')}

Berdasarkan hadis Nabi: Idra' al-Hudud bi al-Syubuhat,para fuqaha berpendapat bahwa hubungan kelamin (wathi') diluar perkawinan yang sah, bila di dalamnya terdapat syubhat (kesamaran), maka kesamaran atau syubhat tersebut dapatdijadikan alasan untuk menolak diberlakukannya had.

Syubhat ada tiga macam menurut al-Syafi'iyah:

Pertama; Syubhat berkaitan dengan obyeknya, ( شبهة فى المحل ) seperti menggauli isteri yang sedang haid, sedang berpuasa, menggauli isteri dengan cara liwath (anal sex).

Kedua; Syubhat berkaitan dengan pelakunya, (شبهة فى الفاعل) seperti bila seseorang menggauli wanita lain yang disangka isterinya sendiri.

Ketiga; Syubhat berkaitan dengan prosedurnya (شبهة فى الطريق) seperti hubungan kelamin yang terjadi dalam pernikahan yang diperselisihkan oleh fuqaha. Umpamanya, pernikahan tanpa wali, Abu Hanifah membolehkannya sedangkan mayoritas fuqaha menolaknya. Demikian pula nikah tanpa saksi, Imam Malik membolehkannya, sedangkan mayoritas fuqaha melarangnya. Nikah mut'ah juga mengandung syubhat, Ibnu Abbas membolehkannya, sementara jumhur fuqaha melarangnya. Demikian seterusnya, setiap bentuk pernikahan yang diperselisihkan, pelakunya tidak dikenai had tetapi dikenai ta'zir. ${ }^{9}$

\footnotetext{
7 Abdul Qadir 'Audah, al-Figh al-Jina'I al-Islami, hlm. 352.

${ }^{8}$ Abdul Qadir 'Audah, al-Figh al-Jina'I al-Islami, hlm. 353.

${ }_{9}$ Abdul Qadir 'Audah, al-Figh al-Jina'I al-Islami, hlm. 360.
} 
Hubungan Kelamin dengan Paksaan (الوطء بالاكر اه )

Bila hubungan kelamin di luar nikah dilakukan dengan jalan paksaan, atau dilakukan di bawah ancaman atau tekanan orang lain, maka yang diancam atau dipaksa itu terbebas dari hukuman. Dalam hal ini Nabi bersabda:

$$
\text { عفى لآمتى عن الخطأ والنسيان وما استكرهوا عليه }
$$

"Dimaafkan atas ummatku perbuatan karena keliru, lupa, dan terpaksa."10

Sedangkan pihak yang memaksa itu tetap dikenai hukuman had. Sebaliknya, jika seorang wanita merelakan dirinya disetubuhi lelaki lain, maka keduanya dikenakan sanksi (had) zina. Karena, hukuman had merupakan hak Allah, sehingga kerelaan masing-masing pihak bukanlah suatu syubhat yang dapat merubah atau menggugurkan sanksi. ${ }^{11}$

\section{Perkawinan Setelah Terjadi Perzinahan (الزواج اللاحق )}

Menurut keterangan Imam Abu Yusuf dari Abu Hanifah, bahwa perkawinan yang diadakan menyusul tindak perzinahan merupakan syubhat yang dapat menolak diberlakukannya had. Sedangkan jumhur fuqaha tetap memandangnya sebagai suatu perzinahan murni yang harus diberi sanksi had, walaupun disusul dengan perkawinan. Perkawinan bukanlah sarana pemutihan atas tindak pelanggaran seksual. Hukumannya tetap yaitu hukuman rajam bagi yang telah kawin, dan dera serta pengasingan bagi yang masih lajang. ${ }^{11}$

\section{Onani (Istimna')}

Onani atau pengeluaran sperma (mani) dengan tidak melakukan senggama menurut al Syafi'iyah dan Malikiyah diharamkan secara mutlak, baik terpaksa karena khawatir zina atau tidak. Sedangkan menurut Abu Hanifah, onani bisa haram bisa pula wajib. Onani haram dilakukan jika sengaja untuk menggugah syahwat. Dan wajib dilakukan jika yang bersangkutan merasa khawatir akan terjerumus ke dalam perzinahan jika

\footnotetext{
10 Ibnu Hazm, al-Muhalla, Jilid 7, hlm. 334.

11 Abdul Qadir 'Audah, al-Figh al-Jina'I al-Islami. hlm, 365.

${ }^{11}$ Abdul Qadir 'Audah, al-Fiqh al-Jina'I al-Islami, hlm. 365.
} 
tidak melakukannya. Alasannya, kaedah Irtikab akhaff al-Dhararain, yaitu memilih tindakan yang tingkat resikonya lebih rendah. Dalam pada itu Ibnu Hazm berpandangan bahwa onani itu makruh hukumnya. Makruh, karena onani bukanlah tindakan yang mencerminkan akhlak mulia. ${ }^{12}$

\section{Penetapan Had Zina}

Adapun penetapan had zina dapat dilakukan melalul pembuktian dengan: a). Pengakuan, b). Kesaksian, c). Kehamilan.

Pertama; Pengakuan (Iqrar). Pengakuan merupakan alat bukti yang kuat dalam menetapkan had zina, sebagaimana Rasulullah Saw. pernah menetapkan had atas perzinahan yang dilakukan oleh Ma'is dan wanita alGhamidiyah. Hanya saja para fuqaha berbeda pendapat dalam hal jumlah pengakuan yang diucapkan. Menurut Imam Malik dan Imam al-Syaf i'i, pengakuan yang diberikan cukup sekali saja. Sedangkan menurut Hanafiyah, pengakuan yang diberikan haruslah empat kali dan diucapkan dalam majelis yang berbeda. ${ }^{13}$

Kedua; Kesaksian. Kesaksian atas perzinahan haruslah diberikan oleh minimal empat orang saksi laki-laki yang kesemuanya adil. Masing-masing saksi haruslah melihat dengan mata kepala sendiri secara nyata masuknya kelamin laki-laki ke dalam liang farji wanita pasangannya bagaikan masuknya stik ke dalam liang tempat celak mata, atau masuknya tali timba kedalam sumur. ${ }^{14}$

Untuk menghadirkan keempat orang saksi yang memiliki kualifikasi tersebut diatas bukanlah sesuatu yang mudah, bahkan hampir mustahil dapat dilakukan. Oleh karena itu, mungkin ini mengandung hikmah mendalam betapa melalui sifat al-Rahman dan al-Rahim-Nya Allah Swt. ingin memelihara kehormatan dan nama baik seseorang yang beriman tentunya, agar tidak mudah dicemarkan nama baiknya oleh orang lain. Perlindungan Allah Swt. seperti ini perlu disyukuri, terutama oleh mereka yang terlanjur melakukan perbuatan terlarang dengan cara bertaubat setulus-tulusnya untuk tidak mengulang lagi perbuatan masa lalu.

${ }^{12} \mathrm{Al}-$ Sayid Sabiq, Figh al-Sunnah, hlm. 367.

${ }^{13} \mathrm{Al}$-Sayid Sabiq, Figh al-Sunnah, hlm. 352.

${ }^{14}$ Al-Sayid Sabiq, Fiqh al-Sunnah, hlm. 356. 
Ketiga; Kehamilan. Pembuktian zina melalui kehamilan belumlah disepakati para fuqaha, bahkan menurut jumhur Ulama, kehamilan saja tidaklah cukup sebagai alat bukti atas perzinahan, tetapi haruslah diperkuat dengan pengakuan atau kesaksian. ${ }^{15}$

Menurut jumhur, kehamilan seorang wanita bisa terjadi karena persetubuhan terpaksa (diperkosa), atau karena wathi' syubhat atau karena disetubuhi dalam keadaan tidak sadar (tidur lelap) atau karena sebab lain. Semua ini dapat dijadikan sebab gugurnya penetapan had. Kehamilan juga bisa terjadi bukan melalui senggama, tetapi melalui suntikan sperma ke dalam liang farji.

Sebagaimana disebut dimuka, bahwa qadzaf yang dikenai hukuman had adalah menuduh zina terhadap orang baik-baik atau menolak nasab seseorang. Tuduhan zina dapat berupa perkataan: "Hai anak zina" atau "Hai anak jadah". Perkataan ini memiliki implikasi ganda; pertama, penolakan nasab atas anak tersebut, dan kedua, tuduhan zina terhadap ibu anak itu. Tuduhan semacam ini dikenai hukuman had. Sedangkan qadzaf yang dikenai hukuman $t a^{\prime} z i r$ adalah seperti tuduhan melakukan kekufuran, korupsi, kolusi, nepotisme, makan riba, pengkhianat bangsa dan sebagainya.

Menurut Fuqaha, rukun qadzaf ada empat, yaitu: a). Tuduhan zina atau penolakan nasab, b). Orang yang dituduh itu orang baik-baik (muhshan), yaitu orang yang aqil baligh, Islam, merdeka, dan terpelihara, c). Ada maksud menodai martabat, d). Orang yang menuduh sudah aqil baligh, bukan ibu bapak atau nenek (dan seterusnya) dari pihak tertuduh, tidak kebal hukum (multazim al-Ahkam) dan tidak dipaksa. ${ }^{18}$

Fuqaha sepakat bahwa tuduhan qadzaf dengan perkataan yang jelas (sharih) diancam dengan hukuman had. Sedangkan bila tuduhan itu disampaikan dengan perkataan metaforis atau sindiran, maka fuqaha berbeda pendapat. Menurut Abu Hanifah perkataan metaforis atau sindiran tidaklah dikenakan sanksi had atasnya. tetapi dikenakan ta'zir. Umpamanya ucapan: "Aku sih bukan pezina", atau "Ibuku bukan pezinah", atau "Ibumu penjaja cinta", "Hai anak si kupu-kupu malam". Menurutnya, perkataan metaforis atau kiasan mengandung kemungkinan penafsiran lain, yang berarti mengandung elemen syubhat. Menurut hadis, bila ada syubhat maka had harus dihindari. Sedangkan menurut al-Syafi'i dan Malik, perkataan kiasan

\footnotetext{
${ }^{15}$ Abdul Qadir 'Audah, al-Figh al-Jina'I al-Islami, hlm. 440.

${ }^{18} \mathrm{Al}-$ Sayyid al-Bakri, I'anah al-Thalibin, hlm. 169.
} 
atau sindiran tetap dikenakan had jika ada niat menodai martabat, atau ada indikasi kearah itu. ${ }^{19}$

Di muka telah disebutkan bahwa syarat orang yang tertuduh adalah muhshan (orang baik), baik laki laki maupun perempuan. Ada perbedaan antara muhshan dalam had zina dengan muhshan dalam had qadzaf. Muhshan dalam had zina tidak diharuskan beragama Islam dan terpelihara dari perzinahan. Sedangkan muhshan dalam had qadzaf disyaratkan beragama Islam dan terpelihara dari perzinahan (iffah).

\section{Minuman Keras (Khamr)}

Yang disebut dengan khamr menurut Abu Hanifah adalah perasan anggur ketika mendidih dan mengeluarkan buih. Minuman khamr ini menurutnya haram diminum baik sedikit atau pun banyak, mabuk ataupun tidak. Illat keharamannya adalah zatnya khamr tersebut. Sedangkan minuman yang terbuat dari selain anggur itu disebut nabidz. Abu Hanifah seperti halnya Ulama Irak lainnya memandang bahwa ada perbedaan antara khamr dengan nabidz tersebut. Khamr haram karena zatnya, sedang nabidz haram karena sifat memabukkannya. ${ }^{21}$

Memang ada perbedaan antara Ulama Hijaz dan Ulama Irak dalam mendefinisikan khamr. Menurut Ulama Hijaz dan Mayoritas Ahlul Hadis, minuman keras yang terbuat dari selain perasan anggur (nabidz) itu haram meminumnya, sedikit ataupun banyak. memabukkan ataupun tidak. Sedangkan Ulama Irak yang didukung oleh Abu Hanibah berpendapat bahwa minuman yang terbuat dari selain anggur (nabidz) itu hukumnya haram kalau memabukkan. Bila sedikit dan tidak memabukkan, maka hukumnya boleh. Jadi yang menjadi illat keharamannya bukanlah zatnya, tetapi sifat memabukkannya itu. Bila seseorang minum nabidz tiga sloki umpamanya dan tidak mabuk maka itu tidak diharamkan. Tetapi jika minum lagi sloki yang keempat kemudian mabuk, maka yang haram adalah minuman sloki yang keempat itu. ${ }^{22}$

Ulama Hijaz tidak membedakan antara khamr dan nabidz. Kaedah yang mereka tetapkan adalah semua minuman yang memabukkan adalah khamr,

${ }^{19}$ Al-Sayyid al-Bakri, I'anah al-Thalibin, hlm. 466.

${ }^{21}$ Al-Syaukani, Nail al-Authar, Jilid 8, hlm. 190

${ }^{22}$ Ibnu Rusyd, Bidayatul Mujtahid, (Jeddah: al-Haramain, tt.), Cet. Ke-3, Jilid 2, hlm. 473. 
dan semua khamr itu haram, sesuai dengan hadis riwayat Ahmad dan Abu Dawud dari Ibnu Umar bahwa Nabi Saw. bersabda:

$$
\text { كل مسكر خمر وكل خمر حرام }
$$

"Setiap yang memabukkan itu khamr dan setiap khamr itu haram."

Juga ada hadis riwayat at-Tarmidzi dan Abu Dawud dariJabir bin Abdullah bahwa Nabi bersabda:

$$
\text { ما اسكر كثيره فقليله حرام }
$$

"Setiap minuman yang memabukkan jika diminum banyak, maka sedikitnya pun haram."

Sedangkan dalil hadis yang dijadikan hujjah bagi Ulama Irak adalah hadis riwayat Abu "Aun al-Tsaqafi dari Abdullah bin Syaddad, dari Ibnu Abbas, bahwa Nabi bersabda:

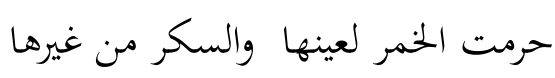

"Khamr diharamkan itu karena zatnya, dan selain khamr itu karena mabuknya". ${ }^{23}$

Allah Swt. berfirman dalam surat al-Ma'idah (5): 91:

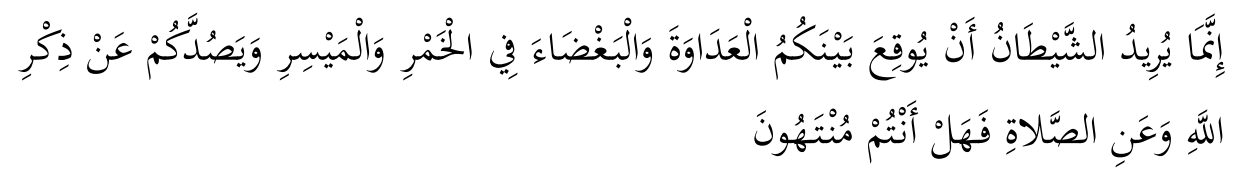

"Sesungguhnya syaitan itu bermaksud hendak menimbulkan permusuhan dan kebencian di antara kamu lantaran (meminum) khamr dan berjudi itu, dan menghalangi kamu dari mengingat Allah dan sembahyang, maka berhentilah kamu (dari mengerjakan pekerjaan itu." (QS. Al-Maidah: 91).

Dari ayat ini diketahui bahwa bahwa illat diharamkannya khamr itu tidak lain karena menghalangi dari mengingat Allah serta menimbulkan permusuhan dan kebencian. Dan illat ini dijumpai pada kadar yang memabukkan, bukan pada kadar yang tidak memabukkan. Maka dari itu kadar yang memabukkan itulah yang diharamkan kecuali apa yang telah menjadi ijma' Ulama tentang keharaman khamrbaik sedikit ataupun banyak. ${ }^{24}$

\footnotetext{
${ }^{23}$ Al-Sayid Sabiq, Figh al-Sunnah, hlm. 320.

${ }^{24} \mathrm{Al}$-Sayid Sabiq, Figh al-Sunnah, hlm. 323.
} 


\section{Had Bagi Peminum Khamar}

Menurut Hanafiyah dan Malik, had bagi peminum adalah 80 kali dera, seperti yang telah dipraktekkan oleh Umar bin Khattab. Sedang menurut alSyafi'i hadnya 40 kali dera, seperti yang pernah dilakukan oleh Nabi Saw., Abu Bakar, dan 'Ali. ${ }^{25}$

Mengingat Nabi sendiri dan Abu Bakar hanya mendera 40 kali dera, sementara perbuatan Nabi tersebut merupakan hujjah yang tidak boleh ditinggalkan, dan tidak boleh ada ijma' atas sesuatu yang menyalahi Nabi. maka dapat dipahami bahwa tambahan yang dilakukan Umar bin Khattab adalah hukuman ta'zir dimana pelaksanaanya tergantung kebijaksanaan Hakim.

\section{Berobat dengan Khamr}

Para Ulama pada umumnya melarang penggunaan khamr sebagai obat, berdasarkan hadis yang melarang hal itu. Dalam hal ini Nabi Saw. bersabda:

$$
\text { إنه ليس بدواء و لكنه داء }
$$

"Khamr bukanlah obat tetapi penyakit"

Akan tetapi sebagian ahli ilmu, memperbolehkan berobat dengan khamr dengan syarat tidak menemukan obat lain selain khamr itu dan bukan dimaksud untuk merasakan kelezatan, serta harus dipergunakan secukupnya. ${ }^{26}$

\section{Penutup}

Demikian uraian pembahasan tentang tindak pidana dalam perspektif hukum Islam. Dari uraian di muka dapat diketahui bahwa berbagai tindak pidana tersebut (al-hudud) jenis sanksinya sudah ditetapkan oleh Allah Swt., baik langsung tertulis dalam Alquran maupun melalui Rasul-Nya yang dihimpun dalam al-hadis. Dalam hal ini berbeda dengan tindak pidana ta'zirdi mana dalam ta'zir, jenis dan kadar sanksinya diserahkan kepada

${ }^{25}$ Al-Sayid Sabiq, Figh al-Sunnah, hlm. 335.
${ }^{26}$ Al-Sayid Sabiq, Figh al-Sunnah, hlm. 340. 
ijtihad Hakim. Hakimlah yang menentukan jenis dan kadar sanksi pidana sesuai dengan situai dan kondisi dimana peradilan berada.

\section{Pustaka Acuan}

al-Bakri, Al-Sayyid, I'anah al-Thalibin, (Beirut: Dar al-Fikr, 1993).

Sabiq, Al-Sayid, Fiqh al-Sunnah, (Beirut: Dar al-Fikr, 1983) Cet. Ke-4, Jilid 2.

'Audah, Abdul Qadir, al-Fiqh al-Jina'I al-Islami, (Beirut: Dar al-Fikr, 1968), Cet. Ke-5, Jilid 2.

Rusyd, Ibnu Bidayatul Mujtahid, (Jeddah: al-Haramain, tt.), Cet. Ke-3, Jilid 2. 